\title{
Associations between the duration and frequency of sedentary bouts and adiposity in elderly community-dwelling women
}

\author{
Jana Pechová ${ }^{*}$, Jana Pelclová ${ }^{1}$, Aleš Gába ${ }^{2}$, Izabela Zajac-Gawlak ${ }^{3}$, Lenka Tlučáková ${ }^{4}$, Jan \\ Dygrýn ${ }^{1}$, Zuzana Svozilová ${ }^{1}$ and Hana Lepková ${ }^{5}$, \\ 1 Institute of Active Lifestyle, Faculty of Physical Culture, Palacký University, Olomouc, Czech Republic \\ 2 Department of Natural Sciences in Kinanthropology, Faculty of Physical Culture, Palacký University, \\ Olomouc, Czech Republic \\ 3 Department of Physical Education, The Jerzy Kukuczka Academy of Physical Education, Katowice, Poland \\ 4 Department of Sport Educology and Humanistic, Faculty of Sports, University of Prešov, Prešov, Slovakia \\ 5 Centre of sports activities, Brno University of technology, Brno, Czech Republic \\ * Correspondence: jana.hodonska@upol.cz; Tel.: +420-585636739
}

\begin{abstract}
Background: This study aimed to describe the frequency and duration of sedentary bouts and assess the bidirectional cross-sectional associations between these characteristics and adiposity in elderly women. 2) Methods: Data from 314 elderly community-dwelling women (mean age 66.6 \pm 6.5 years) from Czech Republic, Poland, and Slovakia were analyzed. Measures were collected in 2008-2017. Fat mass percentage (FM\%) was used as an indicator of adiposity. The patterns of sedentary behaviour were monitored using an accelerometer, and $\geq 5, \geq 10, \geq 20, \geq 30, \geq 40$, and $\geq 60$ minute bouts were analyzed. The exponent alpha was also calculated to express the accumulation of sedentary time in bouts. We performed a multiple linear regression analysis to assess the bidirectional causal association between variables. 3) Results: There was a significant association of $\mathrm{FM} \%$ with time spent in bouts with a duration $\geq 5, \geq 10, \geq 20 \mathrm{~min}$ ( $\beta$ ranging $0.11-0.28$, $\mathrm{p} \leq 0.01$ ) and the frequency of bouts with a length $\geq 5, \geq 10, \geq 20$, and $\geq 30 \mathrm{~min}$ ( $\beta$ ranging 0.03-0.74, $\mathrm{p} \leq 0.05)$ in fully-adjusted models. In contrast, a strong negative association was observed between FM\% and alpha (bout distribution) in both directions ( $\mathrm{p} \leq 0.001)$. 4) Conclusions: Our results suggest that the sedentary characteristics such as bout duration, bout frequency, and distribution (alpha) are bidirectionally associated with adiposity and they should be considered in further research in older adults.
\end{abstract}

Keywords: Adipose tissue; Adiposity; Alpha sedentary; Elderly women; Sedentary bouts

\section{Introduction}

Sedentary behaviour (SB), defined as any waking activity performed in a sitting or reclining posture and requiring $\leq 1.5$ metabolic equivalent of tasks [1], is highly prevalent worldwide [2,3]. It is associated with adverse health outcomes [4,5] and increased risk of mortality [6]. In older adults, who spend a majority of their waking time being sedentary [7], evidence indicating a potentially adverse impact of $\mathrm{SB}$ on health, irrespective of a person's physical activity (PA) levels, is emerging [8]. Hence, SB research including geriatric-relevant health outcomes is essential to develop health promotion strategies that are effective in the elderly [9].

SB can be assessed in different ways, including objective tool-based methods and self-reported events or domain-specific measures such as TV or screen viewing, leisure time sitting, or sitting in a car [10,11]. In addition to total sedentary time, the use of 
accelerometers allows the identification of SB patterns. Subjective observation of sedentary accumulation patterns is challenging for older adults, because they may have difficulties recalling SB during specific timeframe [12]. On the other hand, assessing the total amount of sedentary time in association with adiposity can lead to different results [13] in comparison with studies assessing the different patterns of sedentary time in relation to adiposity [12,13]. Identifying of specific characteristics and sedentary accumulation patterns seems to be important to aging-related outcomes.

Accordingly, sedentary time can be described in terms of bouts of different duration (time in a day or week) and frequencies (times a day or week). Studies employing SB bout analysis in older adults have suggested that most sedentary time occurred in bouts of shorter duration: $<30 \mathrm{~min}$ in men [14] and $<20 \mathrm{~min}$ in women [15]. However, these studies studied only the minutes spent on various bouts of $\mathrm{SB}$, but they did not refer to the actual number of bouts. Deeper investigation of dose-response associations is needed to understand if a different accumulation of SB composed of bouts may have different implications for health. Therefore, not only total sedentary time but also SB characteristics such as the duration or frequency of bouts should be considered.

Older adults' SB might be considered in conjunction with age-related changes in body composition, because fat-free mass tends to decrease with advancing age, whereas body fat mass increases [16-19]. Extensive adiposity might be associated with increased SB or, conversely, might be a barrier to performing regular PA. Whether adiposity is a predictor of SB in the elderly or is a consequence remains unclear. In the older adult population, low PA levels $[17,20]$ and sedentary time [21-26] have been shown to be associated with increase in adiposity. However, the majority of the previous studies used self-reported data. New evidence shows that objective measures show even stronger associations with adiposity [27].

To our knowledge, none of the previously conducted studies investigated the bidirectional causal association between specific patterns of SB (including both the duration and frequency of sedentary bouts) and adiposity in the elderly. Therefore, this study aimed to investigate whether sedentary time accumulated in prolonged bouts displays a linear association with body fatness. We also described the frequency and duration of sedentary bouts and assessed the bidirectional cross-sectional associations between these characteristics and adiposity in a cohort of elderly women from three Central European countries.

\section{Materials and Methods}

\section{Participants and design}

A total of 409 community-dwelling women from Czech Republic, Poland, and Slovakia were recruited from 2008 to 2017. These women attended local senior clubs or were students of the University of Third Age. Women were recruited during face-to-face meetings, at the same time the date of the measurement was arranged. Only volunteers participated in this cross-sectional study. Those who refused to participate are not accounted in the description. All participants had undergone an objective assessment of PA and SB by accelerometers and body composition analysis. All measurements took place during spring (late March to beginning of June) and autumn (October to beginning of December), avoiding extreme weather conditions and seasonal fluctuation in movement behaviours. Women who had undergone major hip or knee surgery in the previous 12 months or who had suffered from a physical handicap that might have interfered with 
body composition and PA measurement (e.g., motor skills disorder, amputation, and paralysis) were excluded from the study. We also excluded women who had used diuretics during the last 12 months.

A written informed consent was obtained from the participants before taking part in the study. The study was approved by the Institutional research ethics committee of the Faculty of Physical Culture of Palacký University Olomouc (No. 20/2016). The ethical principles of the Declaration of Helsinki were adhered to throughout this research.

\section{Adiposity assessment and anthropometric indices}

The standing height was obtained using a portable anthropometer P-375 (Trystom, Olomouc, Czech Republic) with an accuracy of $0.1 \mathrm{~cm}$, and body weight was measured using a bioelectrical impedance analyzer to the nearest $0.1 \mathrm{~kg}$. Body adiposity was expressed as a fat mass percentage $(\mathrm{FM} \%)$ and was measured by a multi-frequency bioelectrical impedance analysis method using the InBody 720 device (Biospace Co., Ltd., Seoul, Korea) with the manufacturer's equations. This method has been considered as sufficiently precise for the assessment of adiposity in the elderly women with different weight status and PA level [28]. To maintain the examination validity, the study participants were instructed to fast for at least $4 \mathrm{~h}$ and maintain proper hydration for at least $24 \mathrm{~h}$ before the examination. All measurements were performed in a standing position while the participants were barefooted and wearing light-weight clothing. The body mass index (BMI) was calculated by dividing body weight (in kilograms) by height (in meters squared). Overweight and obesity were defined as a BMI of $\geq 25$ and $\geq 30 \mathrm{~kg} / \mathrm{m}^{2}$, respectively.

\section{PA and SB assessment}

All participants were asked to wear the ActiGraph GT1M accelerometer (Manufacturing Technology Inc., FL, USA) for at least 8 consecutive days during waking hours, except for water-based activities. The accelerometers were given to the participants immediately after completing the adiposity assessment. The participants were instructed to attach the accelerometer above the right hip on top of their clothing. The time sampling interval of the ActiGraph was set at 1-min epoch. Non-wear time was defined by an interval of 60 consecutive minutes of zero counts per minute (cpm), allowing for $2 \mathrm{~min}$ of non-zero interruptions. To be included in the analysis, $\geq 4$ valid days of monitoring with 10 $h$ of accelerometer wear per day were required [29].

In this study, SB bout was defined as all minutes showing 0-99 cpm [30]. Based on previous studies [31-34], the Central European women are considered as more physically active; therefore, PA was defined according to the cut-off point for adult population - light intensity PA was defined as all minutes in threshold 100-1951 cpm and moderate-to-vigorous PA (MVPA) as all minutes with values $\geq 1952 \mathrm{cpm}$ [30]. Behaviour was considered as sedentary, if the intensity corresponded to the sedentary range and was performed continuously for a certain time interval. We defined six time intervals (bouts) for data analysis: $\geq 5, \geq 10, \geq 20, \geq 30, \geq 40$, and $\geq 60 \mathrm{~min}$. In all cases, a bout was defined as 
consecutive minutes within the SB cpm threshold (0-99 cpm). Bouts with bottom limitation were exported from accelerometer software in the following order: $\geq 5, \geq 10, \geq 20, \geq 30, \geq 40$, and $\geq 60$ minutes, i.e. each bout category is presented as a bout of at least this length or longer $[15,35]$. Total sedentary time was calculated as the sum of all 1-min sedentary intervals. Bout duration (a certain period of continuous sedentary time) and bout frequency (a certain number of times) were calculated and standardized for one week [1]. Moreover, we calculated for the exponent alpha [36,37], which characterizes the frequency distribution of sedentary bouts. Alpha is a unitless measure that indicates if the sedentary time was accumulated rather in relatively longer bouts or relatively shorter bouts with more breaks.

\section{Covariates}

Several variables were used in the analyses to control for variation of these covariates. The analysis was controlled for an accelerometer-based wear time due to high variability in this variable among the study sample. Additionally, we controlled the analysis for several confounding factors that have been identified as strong predictors of SB [10]. This includes demographic (age and employment status), socio-economic (education), health (self-reported health), behavioural (LIPA, MVPA, and smoking status), and environmental factors (living in an apartment). Current employment status was revealed by means of the question "Do you currently have a job?", living arrangements with the question "Do you live in an apartment?", and level of education with the question "Do you have higher education?". Self-reported health was assessed using a single question on the respondents' current health and was classified as "excellent", "very good", "good", "fair", or "poor". This variable was dichotomized, with the first three answers being considered as "good health status". Furthermore, we identified dog owners and participants living in large cities ( $\geq 100,000$ inhabitants) as these factors were strongly associated with SB and PA in older Central European adults $(38,39)$. PA status was assessed objectively, and other covariates were obtained by self-report from participants.

\section{Statistical data analysis}

All analyses were done using the SPSS software, version 22 (SPSS for Windows; SPSS, Chicago, IL). The descriptive statistics were calculated for accelerometry-measured PA and $\mathrm{SB}$, and factors used as covariates; they are presented as the mean, standard deviation, and 95\% confidence interval unless stated otherwise. For current analysis, we excluded the data from those women who did not provide a valid accelerometry data $(n=71)$. Those missing self-reported information used as confounder in the models were also excluded $(n=24)$. The final sample comprised 314 women.

$80 \%$ of the participants had seven days of valid accelerometer data. Thus, all the SB and PA variables that were used were adjusted for the time spent wearing the device and for the device being worn for seven days. We analyzed the associations of the duration and frequencies of several sedentary bouts with adiposity using a multiple linear regression analysis that was adjusted for potential confounding variables. We conducted modeled 
analyses to assess the bidirectional causal association between variables. The factors established as predictors of SB were included as covariates in the multivariable model [10]. In the first analysis, FM\% was used as an independent (exposure) variable. Model 1 represents a model adjusted for age and wear time. It is important to determine whether PA influences SB; thus, model 2 was adjusted for model 1 and MVPA. Light intensity PA was removed from the model as a confounder due to collinearity. The correlation coefficient between light intensity PA and sedentary time was lower than -0.7 . Model 3 was adjusted for model 2 and other confounders. We recalculated these confounders for binary variables. In the second linear regression analysis, bout duration and bout frequency were considered as exposure variables. The regression models were adjusted for the same confounding variables. Finally, in the last analysis, the exponent alpha was assessed.

\section{Results}

\section{Descriptive analysis}

A total of 314 community-dwelling women aged $66.6 \pm 6.5$ years were included in the analysis (Table 1). Almost two-thirds were classified as overweight (42\%) or obese (23\%) based on their body mass index. Women wore the accelerometer on average $13.9 \pm 1.2 \mathrm{~h}$ per day. On average, the women spent $7.8 \pm 1.5,5.4 \pm 1.4$, and $0.6 \pm 0.4$ hours per day in SB, light intensity PA, and MVPA, respectively. Amount of SB is expressed as sedentary bouts of different length $(\geq 5, \geq 10, \geq 20, \geq 30, \geq 40, \geq 60$ minutes/bout). Women accumulated more sedentary bouts lasting $\geq 5, \geq 10, \geq 20, \geq 30$ min than longer sedentary bouts.

Table 1. Descriptive characteristics of the participants $(n=314)$

\begin{tabular}{|c|c|c|c|}
\hline & Mean & SD & $95 \% \mathrm{CI}$ \\
\hline \multicolumn{4}{|l|}{ Age and anthropometrics } \\
\hline Age (years) & 66.6 & 6.5 & $65.9,67.3$ \\
\hline Body height (cm) & 160.9 & 6.5 & $160.2,161.7$ \\
\hline Body weight (kg) & 70.2 & 12.0 & $68.8,71.5$ \\
\hline Body mass index $\left(\mathrm{kg} / \mathrm{m}^{2}\right)$ & 27.1 & 4.4 & $26.6,27.6$ \\
\hline Fat mass percentage $(\%)$ & 36.1 & 7.1 & $35.3,36.9$ \\
\hline \multicolumn{4}{|l|}{ Physical activity } \\
\hline Light intensity physical activity (h/day) & 5.4 & 1.4 & $5.3,5.6$ \\
\hline $\begin{array}{l}\text { Moderate-to-vigorous physical activity } \\
\text { (h/day) }\end{array}$ & 0.6 & 0.4 & $0.6,0.7$ \\
\hline Monitor wear time (h/day) & 13.9 & 1.2 & $13.7,14.0$ \\
\hline \multicolumn{4}{|l|}{ Sedentary behaviour } \\
\hline Sedentary time (h/day) & 7.8 & 1.5 & $7.6,7.9$ \\
\hline Alpha & 1.6 & 0.1 & $1.59,1.61$ \\
\hline
\end{tabular}


Duration of sedentary bouts (h/week)

$\begin{array}{llll}\geq 5 \mathrm{~min} & 42.1 & 11.3 & 40.8,43.4 \\ \geq 10 \mathrm{~min} & 32.3 & 11.0 & 31.1,33.5 \\ \geq 20 \mathrm{~min} & 20.6 & 9.7 & 19.5,21.7 \\ \geq 30 \mathrm{~min} & 13.8 & 8.2 & 12.9,14.7 \\ \geq 40 \mathrm{~min} & 9.4 & 6.8 & 8.7,10.2 \\ \geq 60 \mathrm{~min} & 1.5 & 2.3 & 1.2,1.7\end{array}$

Frequency of sedentary bouts (times/week)

$\begin{array}{llll}\geq 5 \min & 177.2 & 34.2 & 173.4,181.0 \\ \geq 10 \mathrm{~min} & 87.1 & 22.3 & 84.6,89.6 \\ \geq 20 \mathrm{~min} & 34.9 & 13.9 & 33.3,36.4 \\ \geq 30 \mathrm{~min} & 17.6 & 9.2 & 16.6,18.7 \\ \geq 40 \mathrm{~min} & 9.9 & 6.4 & 9.1,10.6 \\ \geq 60 \mathrm{~min} & 1.2 & 1.8 & 1.0,1.4\end{array}$

Weight status, $n$ (\% of $n$ )

Underweight $2(0.6)$

Normal weight 108 (34.4)

Overweight $133(42.4)$

Obesity $71(22.6)$

Self-reported data, $n$ (\% of $n$ )

Higher education (>13 years) $153(49)$

Employed $56(18)$

Living in a flat (not in a house) 199 (63)

Location with $\geq 100$, 000 citizens 173 (55)

Having a pet $60(19)$

Current smoker $14(4.5)$

Abbreviation: $n$, number of participants; $S D$, standard deviation; $C I$, confidence interval

Sedentary time was mainly accumulated in bouts of shorter duration (Figure 1). Women in the last quartile with the highest \%FM collected, on average, more sedentary bouts and they accumulated more minutes in all bout categories. 

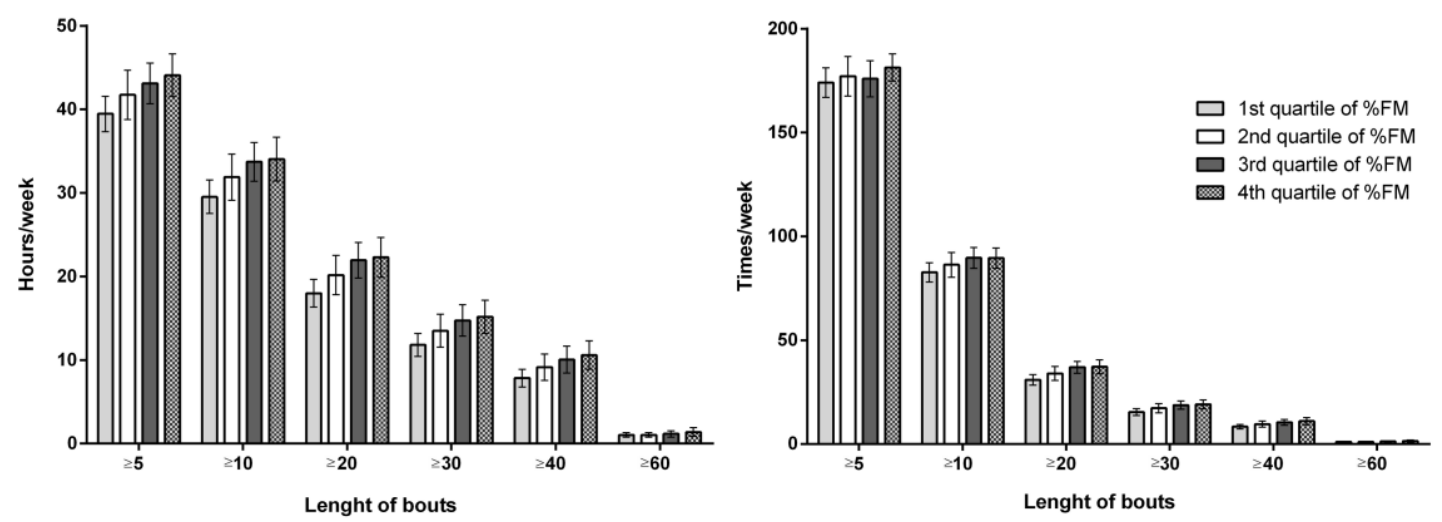

Figure 1. The duration (h/week) and frequency (times/week) bout distribution across quartiles of \%FM.

\section{Duration of sedentary bouts}

When the duration of a sedentary bout was modelled as the exposure, a positive independent association with FM\% was observed (Table 2). After adjustment for all confounders (Figure 2), the sedentary bouts $\geq 20$ min were considered as independent predictors of adiposity $(\beta=0.11, p \leq 0.01)$, and there were no significant associations for longer sedentary bouts. In the third model, one additional hour/week spent in bouts with a duration $\geq 20 \mathrm{~min}$ was associated with 0.11 higher $\% \mathrm{FM}$. From this point of view, fat mass seems a better predictor of SB than the other way around.

Similar results were observed for bout duration, which was considered as an outcome variable (Table 3). In a minimally adjusted model, the associations were significant in all sedentary bouts except for $\geq 60 \mathrm{~min}$ bouts. This association weakened after adjustment for MVPA. After adjustment for all confounders (Figure 2), there were significant associations with bouts with a duration $\geq 5, \geq 10$, and $\geq 20$ min ( $\beta$ ranging from 0.21 to $0.28, p \leq 0.01$ ). Based on Model 3, shown in Table 3, (adjusted for age, wear time, MVPA, socio-demographic, and health confounders), each additional $5 \%$ of fat mass was associated with a 1.05 hour/week increase in the time spent on SB bouts with a duration $\geq 20$ min $(\mathrm{p} \leq 0.01)$.

Table 2. Associations between FM\% (outcome) and sedentary bouts (exposure)

\begin{tabular}{|c|c|c|c|c|c|c|c|c|c|}
\hline & \multicolumn{3}{|c|}{$\begin{array}{l}\text { Model } 1 \\
\text { FM\% }\end{array}$} & \multicolumn{3}{|c|}{$\begin{array}{l}\text { Model } 2 \\
\text { FM\% }\end{array}$} & \multicolumn{3}{|c|}{$\begin{array}{l}\text { Model } 3 \\
\text { FM\% }\end{array}$} \\
\hline & $\beta$ & $\mathrm{R}^{2}$ & $95 \% \mathrm{CI}$ & $\beta$ & $\mathrm{R}^{2}$ & $95 \% \mathrm{CI}$ & $\beta$ & $\mathrm{R}^{2}$ & $95 \% \mathrm{CI}$ \\
\hline \multicolumn{10}{|c|}{ Duration of sedentary bout (hours/week) } \\
\hline$\geq 5$ & $0.15 \ddagger$ & 0.15 & $0.08,0.23$ & $0.10^{+}$ & 0.26 & $0.03,0.17$ & $0.11^{+}$ & 0.31 & $0.04,0.18$ \\
\hline$\geq 10$ & $0.14^{\ddagger}$ & 0.15 & $0.07,0.22$ & $0.10^{+}$ & 0.26 & $0.03,0.17$ & $0.11^{+}$ & 0.30 & $0.03,0.18$ \\
\hline$\geq 20$ & $0.15^{\ddagger}$ & 0.14 & $0.07,0.24$ & $0.10^{*}$ & 0.26 & $0.02,0.18$ & $0.11^{+}$ & 0.30 & $0.03,0.19$ \\
\hline$\geq 30$ & $0.15^{+}$ & 0.13 & $0.05,0.24$ & 0.09 & 0.25 & $-0.01,0.18$ & 0.09 & 0.29 & $-0.001,0.18$ \\
\hline$\geq 40$ & $0.16^{+}$ & 0.13 & $0.04,0.28$ & 0.09 & 0.25 & $-0.02,0.20$ & 0.09 & 0.29 & $-0.02,0.20$ \\
\hline$\geq 60$ & 0.14 & 0.11 & $-0.19,0.48$ & 0.12 & 0.25 & $-0.19,0.42$ & 0.07 & 0.28 & $-0.23,0.38$ \\
\hline
\end{tabular}

Frequency of sedentary bout (number/week) 


\begin{tabular}{llllllllll}
$\geq 5$ & $0.04^{\ddagger}$ & 0.14 & $0.01,0.06$ & $0.02^{*}$ & 0.26 & $0.003,0.05$ & $0.03^{*}$ & 0.30 & $0.01,0.05$ \\
$\geq 10$ & $0.06^{\ddagger}$ & 0.14 & $0.03,0.10$ & $0.05^{+}$ & 0.26 & $0.01,0.08$ & $0.05^{+}$ & 0.30 & $0.02,0.08$ \\
$\geq 20$ & $0.12^{\ddagger}$ & 0.15 & $0.06,0.18$ & $0.08^{+}$ & 0.27 & $0.03,0.14$ & $0.09^{+}$ & 0.31 & $0.03,0.14$ \\
$\geq 30$ & $0.13^{+}$ & 0.13 & $0.04,0.22$ & 0.08 & 0.25 & $-0.001,0.17$ & $0.09^{*}$ & 0.29 & $0.003,0.17$ \\
$\geq 40$ & $0.17^{+}$ & 0.13 & $0.04,0.30$ & 0.10 & 0.25 & $-0.02,0.22$ & 0.10 & 0.29 & $-0.02,0.22$ \\
$\geq 60$ & 0.18 & 0.11 & $-0.26,0.62$ & 0.15 & 0.25 & $-0.26,0.56$ & 0.09 & 0.28 & $-0.32,0.49$ \\
\hline
\end{tabular}

Abbreviation: $F M \%$, fat mass percentage; $\beta$, regression coefficient; $R^{2}$, coefficient of determination; $C I$, confidence interval

Model 1 was adjusted for age and wear time.

Model 2 was adjusted for Model 1 and moderate-to-vigorous physical activity.

Model 3 was adjusted for Model 2 and socio-demographic and health confounders (education, housing, location, health status, smoking status, and employ).

${ }^{*} \mathrm{p}<0.05$

${ }^{+} \mathrm{p}<0.01$

$\ddagger \mathrm{p}<0.001$

Table 3. Associations between sedentary bouts (outcome) and FM\% (exposure)

\begin{tabular}{|c|c|c|c|c|c|c|c|c|c|}
\hline & \multirow{2}{*}{\multicolumn{3}{|c|}{$\begin{array}{l}\text { Model } 1 \\
\text { FM\% }\end{array}$}} & \multirow{2}{*}{\multicolumn{3}{|c|}{$\begin{array}{l}\text { Model } 2 \\
\text { FM\% }\end{array}$}} & \multirow{2}{*}{\multicolumn{3}{|c|}{$\begin{array}{l}\text { Model } 3 \\
\text { FM\% }\end{array}$}} \\
\hline & & & & & & & & & \\
\hline & $\beta$ & $\mathrm{R}^{2}$ & $95 \% \mathrm{CI}$ & $\beta$ & $\mathrm{R}^{2}$ & $95 \%$ CI & $\beta$ & $\mathrm{R}^{2}$ & $95 \%$ CI \\
\hline \multicolumn{10}{|c|}{ Duration of sedentary bout (hours/week) } \\
\hline$\geq 5$ & $0.34^{\ddagger}$ & 0.27 & $0.18,0.50$ & $0.26^{+}$ & 0.28 & $0.09,0.44$ & $0.28^{+}$ & 0.32 & $0.11,0.46$ \\
\hline$\geq 10$ & $0.30^{\ddagger}$ & 0.25 & $0.14,0.46$ & $0.24^{+}$ & 0.26 & $0.06,0.41$ & $0.26^{+}$ & 0.28 & $0.08,0.43$ \\
\hline$\geq 20$ & $0.26^{\ddagger}$ & 0.22 & $0.11,0.40$ & $0.20^{*}$ & 0.23 & $0.04,0.35$ & $0.21^{+}$ & 0.24 & $0.06,0.37$ \\
\hline$\geq 30$ & $0.18^{+}$ & 0.19 & $0.06,0.30$ & 0.13 & 0.20 & $-0.01,0.26$ & 0.14 & 0.21 & $-0.001,0.27$ \\
\hline$\geq 40$ & $0.14^{+}$ & 0.17 & $0.03,0.24$ & 0.09 & 0.18 & $-0.02,0.20$ & 0.10 & 0.19 & $-0.02,0.21$ \\
\hline$\geq 60$ & 0.02 & 0.01 & $-0.02,0.05$ & 0.02 & 0.01 & $-0.03,0.06$ & 0.01 & 0.02 & $-0.03,0.05$ \\
\hline \multicolumn{10}{|c|}{ Frequency of sedentary bout (number/week) } \\
\hline$\geq 5$ & $0.88^{\ddagger}$ & 0.18 & $0.34,1.42$ & $0.67^{*}$ & 0.19 & $0.09,1.25$ & $0.74^{*}$ & 0.26 & $0.16,1.32$ \\
\hline$\geq 10$ & $0.60^{\ddagger}$ & 0.23 & $0.26,0.94$ & $0.49^{+}$ & 0.23 & $0.12,0.85$ & $0.54^{+}$ & 0.27 & $0.16,0.91$ \\
\hline$\geq 20$ & $0.41 \ddagger$ & 0.22 & $0.21,0.61$ & $0.33^{+}$ & 0.23 & $0.11,0.55$ & $0.36^{+}$ & 0.24 & $0.14,0.59$ \\
\hline
\end{tabular}




\begin{tabular}{llllllllll}
$\geq 30$ & $0.21^{+}$ & 0.19 & $0.07,0.34$ & 0.15 & 0.20 & $-0.003,0.30$ & $0.16^{*}$ & 0.21 & $0.01,0.31$ \\
$\geq 40$ & $0.13^{+}$ & 0.17 & $0.03,0.23$ & 0.09 & 0.18 & $-0.02,0.19$ & 0.09 & 0.19 & $-0.02,0.20$ \\
$\geq 60$ & 0.01 & 0.01 & $-0.02,0.04$ & 0.01 & 0.01 & $-0.02,0.04$ & 0.01 & 0.02 & $-0.25,0.04$ \\
\hline
\end{tabular}

Abbreviation: $F M \%$, fat mass percentage; $\beta$, regression coefficient; $R^{2}$, coefficient of determination; $C I$, confidence interval

Model 1 was adjusted for age and wear time.

Model 2 was adjusted for Model 1 and moderate-to-vigorous physical activity.

Model 3 was adjusted for Model 2 and socio-demographic and health confounders (education, housing, location, health status, smoking status, and employ).

${ }^{*} \mathrm{p}<0.05$

$+\mathrm{p}<0.01$

${ }^{\ddagger} \mathrm{p}<0.001$

\section{Frequencies of sedentary bouts}

The frequencies of sedentary bouts, which were considered as exposure variables, were independently associated with $\mathrm{FM} \%$. A significant association was observed in periods $\geq 5, \geq 10, \geq 20$, and $\geq 30$ min ( $\beta$ ranging from 0.03 to $0.09, p \leq 0.05$ ). In the third model, and 10 additional bouts/week $\geq 30$ min long predicted an increase in \%FM of 0.9 .

In a fully adjusted model (Figure 2 ), the frequency of bouts $\geq 5, \geq 10, \geq 20$, and $\geq 30 \mathrm{~min}$ as the outcome variable was significantly associated with FM\% ( $\beta$ ranging from 0.16 to $0.74, p$ $\leq 0.05$ ). Each additional $10 \%$ of fat mass was associated with 1.6 more bouts per week with a duration of $\geq 30 \mathrm{~min}(\mathrm{p} \leq 0.05)$ and with 3.6 bouts/week with a duration of $\geq 20 \mathrm{~min}$. The association weakened in longer bouts. 

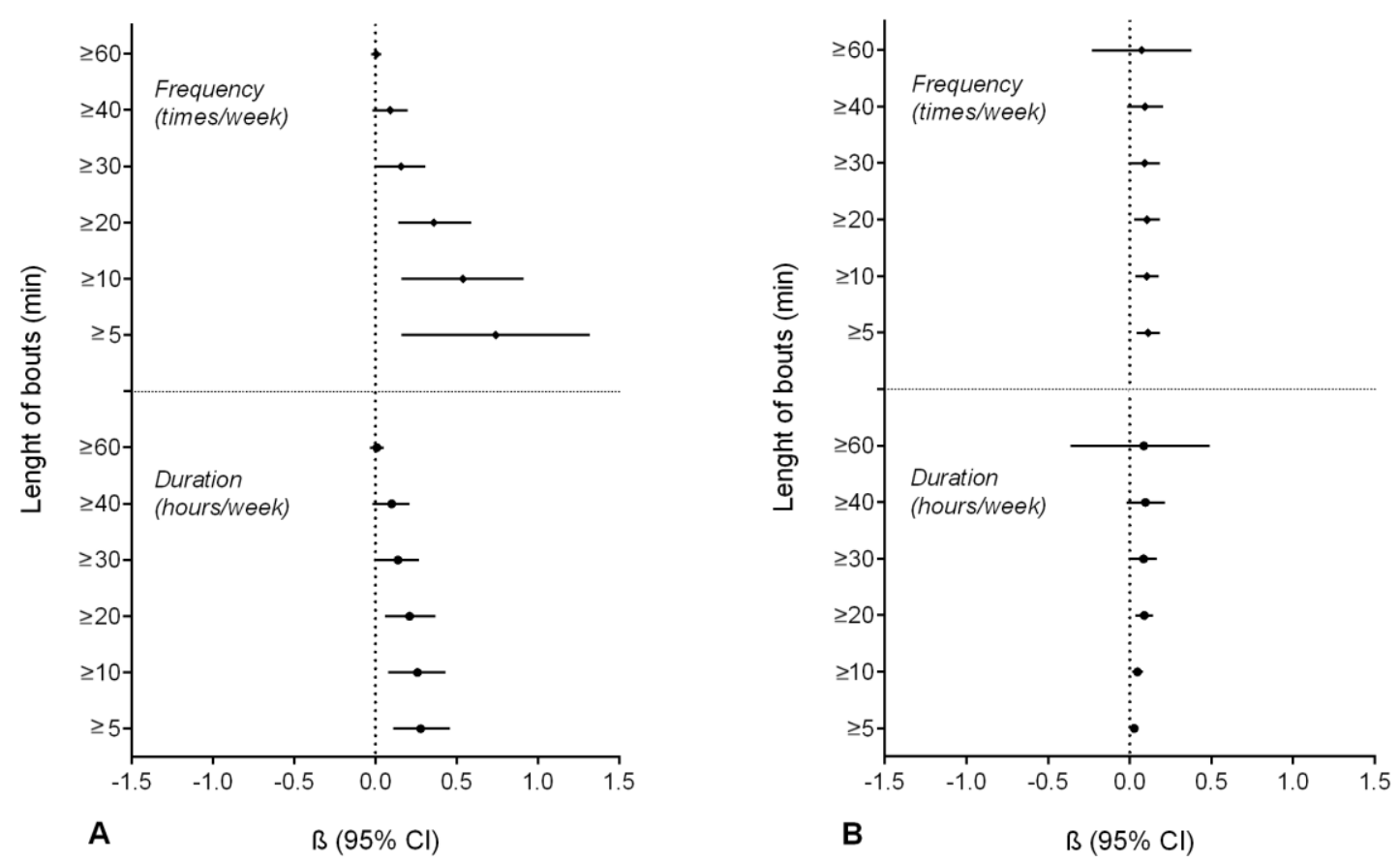

Figure 2. Associations between FM\% (A - exposure; B - outcome) and patterns of sedentary bouts (duration and frequency).

\section{Alpha}

FM\% (exposure) was negatively associated with exponent alpha in the fully adjusted model $(\beta=-0.003 ; p \leq 0.001)$. In contrast, we found a strong negative association in reverse causality $(\beta=-14.37 ; \mathrm{p} \leq 0.001)$. Therefore, not only body fatness influences sedentary patterns, but how SB is accumulated and distributed also influences body fatness.

\section{Discussion}

In this cross-sectional study of elderly women, we found the bidirectional associations between objectively measured adiposity and sedentary bout characteristics. The regression analysis revealed a positive association between adiposity with frequency and duration of sedentary bout measures. The associations weakened, but lasted in bouts within $\geq 5$ to $\geq 20$ min after additional adjustment for covariates, suggesting that the bidirectional causal associations between adiposity and sedentary bout characteristics were independent of age, PA, demographic, socio-economic, and health factors. Our findings extend evidence of accelerometry-measured patterns of SB among community-dwelling older adults in Central European region.

On average, the women in our sample spent sitting less than 8 hours a day. These findings look promising for Central European elderly women because other evidence reported sedentary time accounting for 8.5 hours/day [40] or even 9.4 hours/day [7] in elderly population. The results of the Women's Health Study [15] showed that the mean sedentary time of 9.7 hours/day was accumulated in 86 bouts. Looking at patterns of SB, women accumulated majority of sedentary time in bouts of less than $30 \mathrm{~min}$, which is similar to our study. Japanese elderly women spent also more time in bouts $<30 \mathrm{~min}$, while they have been sitting for more than 8 hours a day [41]. All these findings confirm that older adults spend almost two thirds of their waking time being sedentary [2]. 
Since menopause, elderly women are at higher risk of adiposity. Metabolic transformation in later years can substantially affect women's daily lives, physical condition and it can be a limitation to performing regular PA [42]. Therefore, identification of the relations of SB patterns with adiposity in the elderly is critical to chronic disease prevention.

Although evidence showed that a longer time spent in prolonged sedentary bouts represents a higher risk of adverse metabolic health outcomes [43], bout duration and frequency of sedentary bouts of $\geq 40$ and $\geq 60$ min were not significantly related to body fatness, as reported in the present study. Prolonged sitting was related to adiposity, but despite of the ascending character, this association was not significant. This is in contrast to the conclusions of a cross-sectional study conducted by Jeffferis et al. [14], which involved older men from the United Kingdom. After adjustment for MVPA, short bouts of SB 1-15 min were associated with lower BMI and waist circumference. In unadjusted model, a higher adiposity risk was significantly associated only with sedentary bouts longer than $30 \mathrm{~min}$. Similarly, Honda et al. [43] proved the analogous association in a sample of middle-aged Japanese workers of both genders. In a prospective study, prolonged bouts were associated independently of MVPA with an increased risk of metabolic syndrome over 3 years. They did not found any association with bouts of length less than 20 min or total sedentary time. Moreover, the presented findings confirmed that sedentary bouts of shorter duration are related to adiposity among elderly community-dwelling women, which is probably due to the distribution of sedentary bouts during their day. As shown in Table 1, these women accumulated only a few sedentary bouts of longer duration and the rest of the sedentary time was accumulated in shorter sedentary bouts. Such a rare long period of sitting does not have to play a significant role in the association to adiposity. The most important fact might be a total amount of sedentary time, even when it is accumulated in short periods.

Our results showed that associations between sedentary bouts and FM\% are bidirectional. It corresponds with the conclusions of the prospective study of Golubic et al. [44] conducted in middle-aged individuals. Conversely, other prospective studies in adult sample supported only a one-way association, that BMI or weight gain (exposure) was associated with sitting time and physical inactivity [26,45-49]. The results were somewhat inconsistent and differed in methodology. Three of these studies [47-49] have applied self-report methods, suggesting that the data obtained objectively could prevent measurement biases [27].

This study extends previous findings about sedentary bout characteristics in the elderly and the associations of sedentary time composition with adiposity. In this study, we calculated the exponent alpha, which is a recommended approach if the patterns of SB are of interest [36,37,50], as it indicates the distribution of SB patterns. In the study of Chastin and Granat [37], the exponent alpha ranged from 1.76 to 2.27 in groups with different occupation, age and health status, while total sedentary time did not differ significantly. Different patterns for accumulating sedentary time seem to be affected by overall physical status. Alpha in ethnically diverse cohort of elderly women from the United States $(\mathrm{n}=6166)$ ranged from 1.37 to 2.85 with an average value of 1.87 [51]. As reported in our study, the values of exponent alpha ranged from 1.40 to 2.05 in the Central European elderly women. Hence, the lower values of alpha indicated the accumulation of sedentary time in prolonged bouts with less interruptions. We confirmed the significant negative bidirectional association with adiposity; i.e. body fatness is associated with less fragmented SB. Therefore, the distribution of SB might be an important factor influencing adiposity in elderly women, which should be considered in further research.

\section{Strength and limitations}

A strength of the study is that SB and MVPA were objectively measured using accelerometry. Most importantly, we considered the sedentary characteristics as duration and frequency of sedentary bouts and distribution of sedentary bouts during a day expressed by an exponent alpha. A 
large proportion of recently conducted studies used a self-reported total sitting or TV-viewing time $[7,40]$. To our knowledge, this is the first study investigating the bidirectional associations between adiposity and sedentary bout characteristics in elderly women. Additionally, this is the first detailed investigation of accelerometry-measured SB related to adiposity in the elderly population from the Central European region.

The study has also some limitations. Our sample is smaller than those of larger representative studies. Only healthy elderly community-dwelling women from senior clubs and University of the Third Age classes were included into our study. These women might be more socially and physically active. The average MVPA was 38 min per day, which implies that most of the women were physically active and met the physical recommendations. We used a uniaxial accelerometer, which is widely used for measuring PA and SB, but it may not be sufficiently sensitive to differentiate between physical behaviours such sitting and standing. We were also unable to obtain data on activities such cycling and swimming.

\section{Conclusions}

Our results suggest that the associations between adiposity and sedentary characteristics expressed as bout duration, bout frequency, and distribution of sitting time are bidirectional and independent of age, PA, demographic, socio-economic, and health factors. Shorter bouts were strongly associated with adiposity in elderly women, and the distribution of sedentary time played an important role. Our findings emphasize the benefits of adiposity prevention and treatment with the reduction of long sitting, which can lead to more active and healthy aging. A longitudinal study is needed to verify these associations.

Author Contributions: JPec drafted the manuscript and collected the data. JPel designed the study, performed analyses and collected the data. AG designed statistical models and performed analyses. JD supported in developing the strategy to analyse the data. IZG, LT, ZS, HL collected the data. All of the authors contributed to the design of this study, to the interpretation of the findings and to a critical revision of the manuscript. All of the authors read and approved the final manuscript.

Funding: The study was supported by a research grant from the Czech Science Foundation No. 18-16423S "Influence of obesity on changes in long-term physical activity of older women in context of built environment: a prospective study" and by the internal University Olomouc grant IGA_FTK_2017_004 "Objectively measured sedentary behavior among older women in context of their somatic indicators and quality of life".

Acknowledgments: We would like to thank the women for participating in the study, M. Přidalová and her team for assisting with the collection of body composition data; and D. Pośpiech for collection of PA and SB data.

Conflicts of Interest: The authors declare no conflict of interest.

\section{References}

1. Tremblay MS, Aubert S, Barnes JD, Saunders TJ, Carson V, Latimer-Cheung AE, et al. Sedentary Behavior Research Network (SBRN) - Terminology consensus project process and outcome. Int J Behav Nutr Phys Act. 2017;14(1):75.

2. Hallal PC, Andersen LB, Bull FC, Guthold R, Haskell W, Ekelund U, et al. Global physical activity levels: Surveillance progress, pitfalls, and prospects. Lancet. 2012;380(9838):247-57.

3. Loyen A, Van Der Ploeg HP, Bauman A, Brug J, Lakerveld J. European sitting championship: Prevalence and correlates of self-reported sitting time in the 28 European Union Member 
States. PLoS One. 2016;11(3).

4. Chau JY, Grunseit AC, Chey T, Stamatakis E, Brown WJ, Matthews CE, et al. Daily sitting time and all-cause mortality: A meta-analysis. PLoS One. 2013;8(11):1-14.

5. Pearson N, Braithwaite RE, Biddle SJH, van Sluijs EMF, Atkin AJ. Associations between sedentary behaviour and physical activity in children and adolescents: A meta-analysis. Obes Rev. 2014;15(8):666-75.

6. Ekelund U, Steene-Johannessen J, Brown WJ, Fagerland MW, Owen N, Powell KE, et al. Does physical activity attenuate, or even eliminate, the detrimental association of sitting time with mortality? A harmonised meta-analysis of data from more than 1 million men and women. Lancet. 2016;388(10051):1302-10.

7. Harvey JA, Chastin SFM, Skelton DA. How sedentary are older people? A systematic review of the amount of sedentary behavior. J Aging Phys Act. 2015;23(3):471-87.

8. de Rezende LFM, Rey-López JP, Matsudo VKR, Luiz O do C. Sedentary behavior and health outcomes among older adults: A systematic review. BMC Public Health. 2014;14(1):333.

9. Dogra S, Ashe MC, Biddle SJH, Brown WJ, Buman MP, Chastin S, et al. Sedentary time in older men and women: An international consensus statement and research priorities. Br J Sports Med. 2017.

10. Chastin SFM, Buck C, Freiberger E, Murphy M, Brug J, Cardon G, et al. Systematic literature review of determinants of sedentary behaviour in older adults: A DEDIPAC study. Int J Behav Nutr Phys Act. 2015;12(1):127.

11. Copeland JL, Ashe MC, Biddle SJ, Brown WJ, Buman MP, Chastin S, et al. Sedentary time in older adults: A critical review of measurement, associations with health, and interventions. Br J Sports Med. 2017;51(21).

12. Van Cauwenberg J, Van Holle V, De Bourdeaudhuij I, Owen N, Deforche B. Older adults' reporting of specific sedentary behaviors: Validity and reliability. BMC Public Health. 2014;14(1):1-10.

13. Foong YC, Aitken D, Winzenberg T, Otahal P, Scott D, Jones G. The association between physical activity and reduced body fat lessens with age - Results from a cross-sectional study in community-dwelling older adults. Exp Gerontol. 2014;55:107-12.

14. Jefferis BJ, Parsons TJ, Sartini C, Ash S, Lennon LT, Wannamethee SG, et al. Does duration of physical activity bouts matter for adiposity and metabolic syndrome? A cross-sectional study of older British men. Int J Behav Nutr Phys Act. 2016;13(1):36.

15. Shiroma EJ, Freedson PS, Trost SG, Lee I-M. Patterns of accelerometer-assessed sedentary behavior in older women. JAMA J Am Med Assoc. 2013;310(23):2562-3.

16. Evans WJ, Campbell WW. Sarcopenia and age-related changes in body composition and functional capacity. J Nutr. 1993;123(2 Suppl):465-8.

17. Hughes VA, Frontera WR, Roubenoff R, Evans WJ, Singh MAF. Longitudinal changes in body composition in older men and women: Role of body weight change and physical activity. Am J Clin Nutr. 2002;76(2):473-81.

18. Shimokata H, Andres R, Coon PJ, Elahi D, Muller DC, Tobin JD. Studies in the distribution of body fat. II. Longitudinal effects of change in weight. Int J Obes. 1989;13(4):455-64.

19. Gába A, Přidalová M. Age-related changes in body composition in a sample of Czech women aged 18 to 89 years: a cross-sectional study. Eur J Nutr. 2014;53(1):167-76.

20. Kim Y, White T, Wijndaele K, Sharp SJ, Wareham NJ, Brage S. Adiposity and grip strength as 
long-term predictors of objectively measured physical activity in 93015 adults: The UK Biobank study. Int J Obes. 2017;41(9):1361-8.

21. Recio-Rodríguez JI, Sanchez-Aguadero N, Rodríguez-Sánchez E, Martinez-Vizcaino V, Martin-Cantera C, Patino-Alonso MC, et al. Physical activity and adiposity among the older adults of the EVIDENT study. J Aging Phys Act. 2017;25(2):254-60.

22. Stamatakis E, Davis M, Stathi A, Hamer M. Associations between multiple indicators of objectively-measured and self-reported sedentary behaviour and cardiometabolic risk in older adults. Prev Med (Baltim). 2012;54(1):82-7.

23. Gennuso KP, Gangnon RE, Matthews CE, Thraen-Borowski KM, Colbert LH. Sedentary behavior, physical activity, and markers of health in older adults. Med Sci Sports Exerc. 2013;45(8):1493-500.

24. Gardiner PA, Healy GN, Eakin EG, Clark BK, Dunstan DW, Shaw JE, et al. Associations between television viewing time and overall sitting time with the metabolic syndrome in older men and women: The Australian diabetes obesity and lifestyle study. J Am Geriatr Soc. 2011;59(5):788-96.

25. Gómez-Cabello A, Pedrero-Chamizo R, Olivares PR, Hernández-Perera R, Rodríguez-Marroyo JA, Mata E, et al. Sitting time increases the overweight and obesity risk independently of walking time in elderly people from Spain. Maturitas. 2012;73(4):337-43.

26. Ekelund U, Brage S, Besson H, Sharp S, Wareham NJ. Time spent being sedentary and weight gain in healthy adults: Reverse or bidirectional causality? Am J Clin Nutr. 2008;88(3):612-7.

27. Sabia S, Cogranne P, van Hees VT, Bell JA, Elbaz A, Kivimaki M, et al. Physical activity and adiposity markers at older ages: Accelerometer Vs questionnaire data. J Am Med Dir Assoc. 2015;16(5):7-13.

28. Gába A, Kapuš O, Cuberek R, Botek M. Comparison of multi- and single-frequency bioelectrical impedance analysis with dual-energy $\mathrm{X}$-ray absorptiometry for assessment of body composition in post-menopausal women: Effects of body mass index and accelerometer-determined physical activity. J Hum Nutr Diet. 2015;28(4):390-400.

29. Hart TL, Swartz AM, Cashin SE, Strath SJ. How many days of monitoring predict physical activity and sedentary behaviour in older adults? Int J Behav Nutr Phys Act. 2011;8(1):62.

30. Freedson PS, Melanson E, Sirard J. Calibration of the computer science and applications, inc. accelerometer. Med Sci Sport Exerc. 1998;30(5):777-81.

31. Pelclová J, Gába A, Tlučáková L, Pośpiech D. Association between physical activity (PA) guidelines and body composition variables in middle-aged and older women. Arch Gerontol Geriatr. 2012 Sep;55(2):e14-20.

32. Gába A, Kapuš O, Pelclová J, Riegerová J. The relationship between accelerometer-determined physical activity (PA) and body composition and bone mineral density (BMD) in postmenopausal women. Arch Gerontol Geriatr. 2012;54(3):e315-21.

33. Zając-Gawlak I, Pośpiech D, Kroemeke A, Mossakowska M, Gába A, Pelclová J, et al. Physical activity, body composition and general health status of physically active students of the University of the Third Age (U3A). Arch Gerontol Geriatr. 2016;64:66-74.

34. Zając-Gawlak I, Kłapcińska B, Kroemeke A, Pośpiech D, Pelclová J, Přidalová M. Associations of visceral fat area and physical activity levels with the risk of metabolic syndrome in postmenopausal women. Biogerontology. 2017;18(3):357-66.

35. Diaz KM, Howard VJ, Hutto B, Colabianchi N, Vena JE, Blair SN, et al. Patterns of sedentary 
behavior in US middle-age and older adults: The REGARDS study. Med Sci Sport Exerc. 2016;48(3):430-8.

36. Bellettiere J, Winkler EAH, Chastin SFM, Kerr J, Owen N, Dunstan DW, et al. Associations of sitting accumulation patterns with cardio-metabolic risk biomarkers in Australian adults. PLoS One. 2017;12(6):1-17.

37. Chastin SFM, Granat MH. Methods for objective measure, quantification and analysis of sedentary behaviour and inactivity. Gait Posture. 2010;31(1):82-6.

38. Pelclová J, Vašíčková J, Frömel K, Djordjevic I. Leisure time, occupational, domestic, and commuting physical activity of inhabitants of the Czech Republic aged 55-69: Influence of socio-demographic and environmental factors. Acta Univ Palacki Olomuc Gymnica. 2009;39(3):13-20.

39. Pelclová J, Vašíčková J, Frömel K, Djordjevic I, Palackého U, Bláha L, et al. Vliv demografických faktorů na pohybovou aktivitu a sezení u obyvatel České republiky ve věku 55-69 let. [Influence of socio-demographic and environmental factors on physical aktivity and sittinf of inhabitants of the Czech Republic aged 55-69]. Tělesná Kult. 2008;31(2):109-19.

40. Harvey J, Chastin S, Skelton D. Prevalence of Sedentary Behavior in Older Adults: A Systematic Review. Int J Environ Res Public Health. 2013;10(12):6645-61.

41. Liao Y, Hsu H-H, Shibata A, Ishii K, Koohsari MJ, Oka K. Associations of total amount and patterns of objectively measured sedentary behavior with performance-based physical function. Prev Med Reports. 2018;12:128-34.

42. Lovejoy J, Champagne $\mathrm{C}$, de Jonge L, Xie H, Smith S. Increased visceral fat and decreased energy expenditure during the menopausal transition. Int J Obes. 2008;32(6):949-58.

43. Honda T, Chen S, Yonemoto K, Kishimoto H, Chen T, Narazaki K, et al. Sedentary bout durations and metabolic syndrome among working adults: A prospective cohort study. BMC Public Health. 2016;16(1):888-96.

44. Golubic R, Wijndaele K, Sharp SJ, Simmons RK, Griffin SJ, Wareham NJ, et al. Physical activity, sedentary time and gain in overall and central body fat: 7-year follow-up of the ProActive trial cohort. Int J Obes. 2015;39(1):142-8.

45. Pulsford RM, Stamatakis E, Britton AR, Brunner EJ, Hillsdon MM. Sitting behavior and obesity: Evidence from the Whitehall II study. Am J Prev Med. 2013;44(2):132-8.

46. Petersen L, Schnohr P, Sørensen TIA. Longitudinal study of the long-term relation between physical activity and obesity in adults. Int J Obes. 2004;28(1):105-12.

47. Pedisic Z, Grunseit A, Ding, Chau JY, Banks E, Stamatakis E, et al. High sitting time or obesity: Which came first? Bidirectional association in a longitudinal study of 31,787 Australian adults. Obesity. 2014;22(10):2126-30.

48. Bak H, Petersen L, Sørensen TIA. Physical activity in relation to development and maintenance of obesity in men with and without juvenile onset obesity. Int J Obes. 2004;28(1):99-104.

49. van Uffelen JGZ, Watson MJ, Dobson AJ, Brown WJ. Sitting time is associated with weight, but not with weight gain in mid-aged Australian women. Obesity. 2010;18(9):1788-94.

50. Byrom B, Stratton G, Mc Carthy M, Muehlhausen W. Objective measurement of sedentary behaviour using accelerometers. Int J Obes. 2016;40(11):1809-12.

51. Bellettiere J, Healy GN, LaMonte MJ, Kerr J, Evenson KR, Rillamas-Sun E, et al. Sedentary behavior and prevalent diabetes in 6166 older women: The Objective Physical Activity and 
Cardiovascular Health Study. Journals Gerontol Ser A. 2018 May 3;gly101. 